\title{
History-indicated transvaginal cerclage: results from a single-centre
}

\author{
Carolina C. Gomes*, Diana C. Almeida, Elisabete Gonçalves, Ana P. Silva
}

Department of Gynaecology, Obstetrics and Human Reproduction, Centro Hospitalar Universitário do Algarve, Unidade Faro, Faro, Portugal

Received: 05 August 2019

Accepted: 11 September 2019

\section{*Correspondence:}

Dr. Carolina C. Gomes,

E-mail: cigomes@chalgarve-min.saude.pt

Copyright: () the author(s), publisher and licensee Medip Academy. This is an open-access article distributed under the terms of the Creative Commons Attribution Non-Commercial License, which permits unrestricted non-commercial use, distribution, and reproduction in any medium, provided the original work is properly cited.

\section{ABSTRACT}

Background: Cervical incompetence occasionally results in mid-trimester pregnancy loss, preterm labour and increased foetal morbimortality. History-indicated cerclage is proposed when obstetric history suggests cervical incompetence. The aim of this study was to evaluate the maternal-foetal outcomes following prophylactic cervical cerclage.

Methods: Retrospective study reviewing data of all women undergoing transvaginal history-indicated cerclage from January $1^{\text {st }}, 2008$ to December $31^{\text {th }}, 2017$ at Centro Hospitalar Universitário do Algarve - Faro. Primary outcome: gestational age <37weeks at birth. Secondary outcomes: neonatal morbimortality and intensive care unit (NICU) admission and maternal morbidity. Data were analyzed with IBM SPSS Statistics 23.

Results: A total of 12 history-indicated cerclages were performed ( 9 women). At first cerclage, mean maternal age, gestity, parity and live children were $27.6,2.44,1.11$ and 0.78 (87.7\% preterm), respectively. At cerclage placement, mean gestational age and cervical length were 16.1 weeks and $27.5 \mathrm{~mm}$. Average hospital admission was 10.7 days. In all cases McDonald technique was performed. Four hospital readmissions occurred for threatened labour. Mean gestational age at cerclage removal was 36.9 weeks (83.3\% in ambulatory) and 38.9 at delivery. Average time between cerclage removal and labour was 14.5 days. Spontaneous onset of labour occurred in $75 \%$ and vaginal delivery in $83.4 \%$. There were no reports of preterm birth, foetal admission to NICU or maternal complications. Mean number of live children after procedure was 1.58 .

Conclusions: Prophylactic cervical cerclage seems to improve pregnancy outcome with minimal maternal risks. However, our data suggest over inclusion of women, with unnecessary procedures, emphasizing the importance of reevaluating inclusion criteria.

Keywords: Cervical cerclage, Cervical stitch, Cervical insufficiency, Cervico-isthmic incompetence, Preterm birth, Pregnancy loss

\section{INTRODUCTION}

Prematurity is a major cause of neonatal and infant morbidity and mortality. ${ }^{1}$ Several causes, maternal and foetal, can originate cervical modifications in late second and early third trimester and result in pre-/periviable pregnancy loss or premature delivery. ${ }^{2}$ Recognized risk factors for cervical incompetence include either congenital (müllerian anomalies, deficiencies in colaggen, elastine or connective tissue disease, and in utero exposure to diethylstibestrol) or acquired conditions (surgical trauma to the cervix, obstetric lacerations). Certain features of past (prior preterm birth, prior second trimester loss, induced abortion) or current pregnancy (cervical funnelling, multifetal pregnancy) may also increase the risk. ${ }^{1,3,4}$ The relative importance of such 
factors varies between women and between subsequent pregnancies. ${ }^{1,3}$ It is difficult to ascertain the incidence of true cervical insufficiency, although data suggest estimates of $1 \%$ of women. ${ }^{2}$

The cervix is a relatively homogeneous structure, constituted mainly of collagen with very low cellular content, structural and physiologically different from the uterus. It's function, in normal pregnancy, is to retain the foetus in uterus initially and later easily allow passage and delivery, regaining retentive capacity subsequently. ${ }^{2,3}$

Cervical insufficiency is classically defined as an asymptomatic (or painless) dilation and effacement of the cervix resulting in mid-trimester pregnancy loss or early preterm birth. ${ }^{2}$ Since clinical criteria and diagnosis are difficult to establish and vary according to literature, its diagnosis is frequently made with a retrospective history of poor obstetric outcome.

As almost one in four women who have had a previous early spontaneous preterm delivery will recur in a subsequent pregnancy, several strategies to improve outcome have been proposed.

The cervix, regardless of whether the primary problem is, remains a logical target to intervein, even though it is unclear if cerclage will be beneficial to all women under this circumstances. ${ }^{2}$

Several cerclage techniques have arisen and evolved since its introduction in the 1950's. Its indications have been growing, from history of recurrent mid-trimester pregnancy loss to progressive cervical alterations and objective cervix dilation and effacement. This resulted in three types of cerclage: history-indicated (also known as prophylactic or primary), ultrasound-indicated (therapeutic or secondary) and physical exam-indicated cerclage (emergency, rescue or tertiary)., ${ }^{4,5}$ Even for history-indicated guidelines criteria for performance varies widely worldwide, from history of 3 or more previous second-trimester pregnancy losses or preterm deliveries contrasting to history of 1 or more secondtrimester pregnancy loss related to painless cervical dilation in the absence of labour or placental abruption. ${ }^{4}$ Uniformity is required.

The aim of this study is to evaluate the maternal-foetal outcomes following prophylactic cervical cerclage at a level III perinatal care unit in Portugal.

\section{METHODS}

This is a hospital based, single-centre, retrospective study which reviewed data of all cases of women undergoing transvaginal history-indicated cervical cerclage from January $1^{\text {st }}, 2008$ to December $31^{\text {st }}, 2017$ at Centro Hospitalar Universitário do Algarve - Unidade Faro. Inclusion criteria met the American College of Obstetrics and Gynaecology (ACOG) Guideline indications for history-indicated cerclage: History of one or more second-trimester pregnancy losses related to painless cervical dilation and in the absence of labour or abruption placentae and/or prior cerclage due to painless cervical dilation in the second trimester. Excluding criteria consisted of follow up loss. Once the women were identified, all hospital records were obtained from the time of admission for cerclage placement to delivery, as well as data from previous pregnancies when available. Data on demographics, personal history, obstetric history, pregnancy, delivery and neonatal period were obtained. The primary outcome was gestational age $<37$ weeks at birth. Secondary outcomes included hospital readmission during pregnancy, maternal morbidity, neonatal intensive care unit (NICU) admission and neonatal overall morbidity.

\section{Statistical analysis}

Data were analysed with IBM SPSS Statistics 23. Descriptive frequencies were used to present the results.

\section{RESULTS}

A total of 12 interventions (corresponding to 9 women) met the criteria and were involved in the study. Mean maternal age at the time of first cerclage was 27.6 years \pm 4.39; when including recurrent cerclages, mean gestational age was 28.25 years \pm 4.90 . At the time of first cerclage women had a mean of 2.44 previous gestations, a mean parity of 1.11 and only $50 \%$ of women had a previous live child (a mean of 0.78 live children) $87.7 \%$ of these being born preterm. The presence of known risk factors for cervical insufficiency was found in a minority (previous dilation and curettage and conization); no medical co-morbidities were identified. Demographics, obstetric history and risk factors are summarized in Table 1.

Table 1: Demographics, obstetric history and risk factors.

\begin{tabular}{|ll|}
\hline Age at first cerclage (years) $(\mathbf{n}=9)$ & \\
\hline Mean \pm SD & $27.56 \pm 4.39$ \\
\hline Median & 28 \\
\hline Range & $20-34$ \\
\hline Age (years) (n= 12) & \\
\hline Mean \pm SD & $28.25 \pm 4.90$ \\
\hline Median & 28 \\
\hline Range & $20-38$ \\
\hline Gravidity, mean (range) & $2.44(1-4)$ \\
\hline Parity, mean (range) & $1.11(1-4)$ \\
\hline Reproductive history & \\
\hline Prior preterm birth (\%) & 83.4 \\
\hline Prior spontaneous abortion (\%) & 65.6 \\
\hline Risk factors for cervical insufficiency \\
\hline Cervical dilation for curetage (\%) \\
\hline Conization (\%) & 22.2 \\
\hline
\end{tabular}

n: number of cases; SD: standard deviation; \%: percentage. 
In all cases McDonald technique was performed. Mean gestational age at hospital referral was 12.1 weeks \pm 2.76 with mean cervical length $35.1 \mathrm{~mm} \pm 5.13$. At the time of cerclage placement, mean gestational age was 16.1weeks \pm 0.51 and mean cervical length $27.5 \mathrm{~mm} \pm 8.70$. Hospital admission lasted on average 10.7 days. Four hospital readmissions occurred: 3 for threatened preterm labour and 1 for falsely assumed beginning of labour.

Table 2: Cerclage placement and removal and foetal and maternal outcomes.

\begin{tabular}{|ll|}
\hline Gestational age at cerclage placement & (weeks) \\
\hline Mean \pm SD & $16.1 \pm 0.51$ \\
\hline Range & $15-17$ \\
\hline Cervical length at placement (mm) & \\
\hline Mean \pm SD & $27.5 \pm 8.70$ \\
\hline Range & $10-38$ \\
\hline Gestational age at cerclage removal (weeks) \\
\hline Mean \pm SD & $36.9 \pm 0.30$ \\
\hline Range & $36-37$ \\
\hline Time from removal to delivery (days) \\
\hline Mean \pm SD & $14.5 \pm 9.35$ \\
\hline Range & $1-28$ \\
\hline Live birth (\%) & 100 \\
\hline Weight at birth (g) Mean \pm SD & $3440.8 \pm 496.9$ \\
\hline Apgar index $>7$ at min 5 (\%) & 100 \\
\hline Neonatl jaundice $(\%)$ & 33.3 \\
\hline Need for phototherapy (\%) & 11.1 \\
\hline NICU admission & 0 \\
\hline Maternal complications & 0 \\
\hline SD: & \\
\hline
\end{tabular}

SD: standard deviation; \%: percentage; $\mathrm{NICU}=$ neonatal intensive care unit.

Removal of cerclage was made in ambulatory environment in $83.3 \%$ of cases. Mean gestational age at cerclage removal was 36.9 weeks and at delivery was 38,9 weeks, with average time between cerclage removal and labour being 14.5 days (range 1-28 days). Spontaneous onset of labour occurred in $75 \%$ of women, the remaining cases corresponding to induction of labour due to gestational diabetes or prolonged pregnancy. Delivery occurred vaginally in $83.4 \%$. Caesarean section was performed in one case second to premature detachment of normally inserted placenta (PDNIP). Data on cerclage placement and removal and foetal and maternal outcomes are summarized in Table 2. No cases of preterm birth or stillbirth occurred. Neonates were female in $63.6 \%$ of case, weighted $3440.8 \mathrm{~g}$ in average and Apgar index was above 7 at 5 minutes in all cases. Neonatal jaundice was observed in $25 \%$ of newborns, but no cases of respiratory distress, sepsis or major malformations were described. No cases were reported of foetal admission to NICU. There were no maternal complications.

After the intervention pregnancy, $100 \%$ of women had a live child, resulting in a mean number of live children of 1.58 .

\section{DISCUSSION}

This analysis of hospital data reports a high rate of success after history-indicated cervical cerclage.

Similar results were found in the literature regarding history-indicated elective cerclage, achieving prevention of second trimester loss (STL) or preterm birth (PTB) in two thirds of low-risk groups (defined by one or two prior STL or PTB or by one previous successful cerclage).$^{6-8}$

In this study one limitation may result from indication criteria. The indication for cerclage was at least one previous second trimester spontaneous pregnancy loss where no other cause was identified, conflicting with some recommendations were history of more pregnancy losses is required, hampering comparison. ${ }^{4}$ This fact may falsely improve outcomes, including women with less severe incompetence or better a priori outcome. However, cerclage was offered with these criteria to avoid a repeated miscarriage, weighting the psychological damage of a subsequent pregnancy loss.

In alternative, more strict criteria may result in very few eligible patients for history-indicated cerclage, thus decreasing the number of women benefiting from the procedure. ${ }^{9}$

Another limitation of this study is the reduced number of cases, either due to unregistered or lost cases from older registries or to low rate of cerclage proposal due to medical lack of confidence on ensuring the procedure. This limitation makes it inappropriate to generalize and over interpret the findings.

Since prematurity is a major cause of neonatal morbidity and mortality, with significant costs, a large number of interventions have been proposed for its prevention, some of which non-invasive. More recent systematic reviews and meta-analysis have compared progesterone, cerclage and pessary in decreasing preterm birth, with controversial results: one concluding that vaginal progesterone was the only intervention with consistent effectiveness for preventing preterm birth in singleton atrisk pregnancies whereas another defends that cervical cerclage showed clear benefit for women with singleton pregnancy and high risk of PTB. ${ }^{10,11}$ These alternatives were not considered for our patients as progesterone use in this context is a very recent recommendation and pessary is not available in our country.

\section{CONCLUSION}

Debate persists regarding strategies for decreasing preterm birth. Our results may show an over inclusion of women, when using only one prior pregnancy loss, resulting in unnecessary procedures. But, on the other hand, no maternal complications occurred. Thus, cervical cerclage might be an effective method to lower prematurity if provided for appropriately elected women, 
emphasizing the importance of re-evaluating the criteria for prophylactic cerclage.

Funding: No funding sources Conflict of interest: None declared

Ethical approval: Not required

\section{REFERENCES}

1. Roman A, Suahg A, Berghella V. Overview of cervical insufficiency: diagnosis, etiologies and risk factors. Clin Obstet Gynecol. 2016;59(2):237-40.

2. Shennan A, Jones B. The cervix and prematurity: aetiology, predictions and prevention. Seminars Fetal Neonatal Med. 2004;9:471e479.

3. Vinka J, Feltovich H. Cervical etiology of spontaneous preterm birth. Semin Fetal Neonatal Med. 2016;21(2):106-12.

4. Sperling JD, Dahlke JD, Gonzalez GM. Cerclage use: a review of 3 national guidelines. Obstet Gynecol Sur. 2017;72(4):235-41.

5. Roman A, Suahg A, Berghella V. Cerclage: indications and patient counseling. Clin Obstet Gynecol. 2016;59(2):264-9.

6. Okusanya BO, Isabu PA. Outcome of pregnancy with history-indicated cervical cerclage insertion in a low resource setting. J Matern Fetal neonatal Med. 2015;28(3):284-7.
7. Ikimalo JI, Izuchukwu KE, Inimgba N. Pregnancy outcome after cerclage for cervical incompetence at the University of Port Harcourt Teaching Hospital, Port Harcourt. Afr J Reprod Health. 2012;16(3):180-4.

8. Korb D. Effectiveness of elective cervical cerclage according to obstetric history. J Gynecol Obstet Hum Reprod. 2017;46(1):53-9.

9. Chan LL. Indications for and pregnancy outcomes of cervical cerclage: 11-year comparison of patients undergoing history-indicated, ultrasound-indicated or rescue cerclage. Hong Kong Med J. 2015;21(4):310-7.

10. Jarde A, Lutsiv O, Bevene J, McDonald SD. Vaginal progesterone, oral progesterone, 17-OHPC, cerclage and pessary for preventing preterm birth in at risk singleton pregnancies: an updated systematic review and network meta-analysis. BJOG. 2018.

11. Medley N, Vogel JP, Care A, Alfirevic Z. Interventions during pregnancy to prevent preterm birth: an overview if Cochrane systematic reviews. Cochrane Database Syst Rev. 2018;11:CD012505.

Cite this article as: Gomes CC, Almeida DC, Gonçalves E, Silva AP. History-indicated transvaginal cerclage: results from a single-centre. Int J Reprod Contracept Obstet Gynecol 2019;8:4062-5. 